\title{
Fluid management during video-assisted thoracoscopic surgery for lung resection: A randomized, controlled trial of effects on urinary output and postoperative renal function
}

\author{
Idit Matot, MD, ${ }^{\mathrm{a}}$ Elia Dery, MSc, ${ }^{\mathrm{a}}$ Yuri Bulgov, MD, ${ }^{\mathrm{a}}$ Barak Cohen, MD, ${ }^{\mathrm{a}}$ Joseph Paz, MD, ${ }^{\mathrm{b}}$ and \\ Nachum Nesher, MD $^{\mathrm{b}}$
}

\begin{abstract}
Background: Increased perioperative fluid administration is an independent risk factor for lung injury after pulmonary resection. In clinical practice, fluid therapy is heavily guided by urinary output; however, diuretic response to plasma volume expansion has been reported to be blunted during anesthesia and surgery. We therefore hypothesized that in patients undergoing video-assisted thoracoscopic surgery, different regimens of intraoperative fluid management would not affect urinary output as would be expected in the nonsurgical scenario. Moreover, a restrictive perioperative fluid approach, as indicated in these operations, will not harm renal function.
\end{abstract}

\begin{abstract}
Methods: One hundred two patients undergoing video-assisted thoracoscopic surgery were randomly allocated to receive intraoperatively either high $(8 \mathrm{~mL} /[\mathrm{kg} \cdot \mathrm{h}] ; \mathrm{n}=51)$ or low $(2 \mathrm{~mL} /[\mathrm{kg} \cdot \mathrm{h}] ; \mathrm{n}=51)$ amounts of Ringer's lactate solution. The primary end point was intraoperative urinary output. Secondary end points included postoperative creatinine serum levels and postoperative complication rate.

Results: Demographic and surgical data were comparable between groups. Regardless of the intraoperatively fluids administered (mean \pm SD, $2131 \pm 850$ vs $1035 \pm 652 \mathrm{~mL}$ in high and low groups, respectively; $P<.0001$ ), urinary output was similar (median $300 \mathrm{~mL}$ ). Perioperative creatinine serum levels decreased significantly postoperatively and were not significantly different among the groups.

Conclusions: In patients undergoing video-assisted thoracoscopic surgery, intraoperative urinary output and postoperative renal function are not affected by administration of fluids in the range of 2 to $8 \mathrm{~mL} /(\mathrm{kg} \cdot \mathrm{h})$. The clinical practice of administering fluids to enhance diuresis in the perioperative period should therefore be abandoned. (J Thorac Cardiovasc Surg 2013;146:461-6)
\end{abstract}

Excessive perioperative fluid administration has been shown to promote postoperative lung injury after pulmonary resection. ${ }^{1-7}$ It is therefore recommended to limit the volume of infused crystalloids in these operations. A recent survey of current hemodynamic management practices among patients undergoing surgery in Europe and in the United States reported urinary output as one of the most widely used indications for volume expansion in the perioperative period. ${ }^{8}$ Intraoperative low diuresis often initiates several actions, among them the administration of intravenous fluids. Several recent studies, though, have suggested that renal clearance of crystalloid fluid during general anesthesia and surgery is only $15 \%$ to $20 \%$ of that found in conscious volunteers. ${ }^{9-11}$

\footnotetext{
From the Departments of Anesthesiology, Pain, and Intensive Care ${ }^{\mathrm{a}}$ and Cardiothoracic Surgery, ${ }^{\mathrm{b}}$ Tel Aviv Medical Center, Tel Aviv University, Tel Aviv, Israel. Disclosures: Authors have nothing to disclose with regard to commercial support. Received for publication Oct 8, 2012; revisions received Jan 12, 2013; accepted for publication Feb 12, 2013; available ahead of print April 3, 2013.

Address for reprints: Idit Matot, MD, Department of Anesthesiology, Pain, and Intensive Care, Tel Aviv Medical Center, 6 Weitzman St, Tel Aviv, Israel (E-mail: iditm@tlvmc.gov.il).

$0022-5223 / \$ 36.00$

Copyright (C) 2013 by The American Association for Thoracic Surgery

http://dx.doi.org/10.1016/j.jtcvs.2013.02.015
}

We therefore performed a randomized control trial of high versus low-volume intraoperative fluid management in patients undergoing video-assisted thoracoscopic surgery (VATS) for lung resection. We hypothesized that in this patient population, different regimens of intraoperative fluid protocols (low and high volume approach) would not affect urinary output or perioperative renal function. If data from this study suggest that urinary output during VATS is unresponsive to fluid administration, then the routine administration of more fluids to enhance diuresis during these operations should be reevaluated.

\section{MATERIALS AND METHODS Study Population}

This study was approved by the local ethics committee of Tel Aviv Medical Center, Tel Aviv, Israel (approval 0502-08; trial registry at http:// clinicaltrials.gov NCT00854386) and written, informed consent was obtained from all patients. From December 2010 until May 2012, successive adult patients with an American Society of Anesthesiologists (ASA) physical status of 1 through 3 who were undergoing elective VATS were prospectively studied. Patients were considered eligible if they were older than 18 years and were scheduled to undergo multiple ( $\geq 2$ segments) thoracoscopic segmentectomy or lobectomy. Excluded from the study were patients younger than 18 years, patients with renal dysfunction (creatinine $>50 \%$ upper limit of reference range, which is $1.3 \mathrm{mg} / \mathrm{dL}$ for men and $1.1 \mathrm{mg} / \mathrm{dL}$ for women), and patients with congestive heart failure (previous 


\section{Abbreviations and Acronyms}

ASA $=$ American Society of Anesthesiologists

$\mathrm{RL} \quad=$ Ringer's lactate solution

POD $=$ postoperative day

VATS $=$ video-assisted thoracoscopic surgery

history of pulmonary edema as defined by clinical and radiologic signs that required a change in medication involving at minimum treatment with diuretic drugs). After informed consent was obtained, patients were randomly assigned to a high- or low-volume protocol group with an online randomization software tool.

\section{Study Design and Treatments}

Operative technique. All procedures were performed by 1 of 2 dedicated general thoracic surgeons (J.P., N.N.). The patients were placed in the lateral decubitus position as for thoracotomy. The procedures were performed with patients under general anesthesia with single-lung ventilation through a double-lumen endotracheal tube. The surgeon was positioned on the anterior side of the patient. All procedures were conducted under videoscopic vision, without direct vision or rib spreading. Three incisions were used in each patient. The first port was the inferior camera port located at the seventh or eighth intercostal space, through which a $30^{\circ}$ thoracoscope was positioned. The anterior port was usually in the fourth or fifth intercostal space. The third port was usually in the sixth intercostal space in the posterior axillary line. The individual vascular and bronchial structures were divided with an endoscopic stapling device. A single chest tube was inserted at the lower port site at the end of the procedure. Conversion to thoracotomy was at the discretion of the attending surgeon. Overall, there were 7 conversions to open thoracotomy, 3 in the low-volume group and 4 in the high-volume group, because of large tumors $(\mathrm{n}=3)$, interference of lymph nodes $(\mathrm{n}=3)$, and bleeding $(\mathrm{n}=1)$. These patients were not included in the final data. Patients were generally extubated in the operating room and transferred to the surgical intensive care unit.

Intraoperative fluid management. Patients in the low-volume group received $2 \mathrm{~mL} /(\mathrm{kg} \cdot \mathrm{h}$ ) of Ringer's lactate solution (RL) throughout the intraoperative period, whereas patients in the high-volume group received $8 \mathrm{~mL} /(\mathrm{kg} \cdot \mathrm{h})$ of RL. No additional boluses of fluid were administered before skin incision, and all hemodynamic changes during this period were treated pharmacologically. Intraoperative fluid treatment of low blood pressure ( $<90$ or $>20 \%$ below baseline) in both groups was guided by a fluid algorithm (Figure 1). Generally, fluid boluses ( $250 \mathrm{~mL} \mathrm{RL}$ ) were administered when low blood pressure was encountered on 2 consecutive measurements. Additional boluses of RL were administered to a maximum of $1000 \mathrm{~mL}$. Patients were reassessed after each fluid challenge for $5 \mathrm{~min}$ utes to determine whether target hemodynamic values were achieved. If blood pressure did not improve after 4 consecutive boluses, a pharmacologic circulatory support was used. The fluid regimen was continued until admission to the surgical intensive care unit, where departmental routines ensued. Management of surgical hemorrhage in both groups was done according to a preset algorithm (Figure 1). Blood products were transfused according to the ASA practice guidelines transfusion protocol. ${ }^{11}$

Operative time, urinary output, and doses of drugs (vasopressors) given during the surgical procedure were recorded.

Postoperative management. In the postoperative period, departmental routines guided fluid therapy. Postoperative follow-up included recording of the volumes of crystalloids administered intravenously in postoperative days (PODs) 1 through 3 and the units of blood and blood products (if given) until hospital discharge. Oxygen saturation, hematocrit, electrolytes, blood urea, and creatinine serum concentrations were also measured on PODs 1 through 3 and before discharge. All measurements were made in the morning. Additional blood tests, electrocardiography, and measurements of cardiac enzymes were performed as clinically indicated. After the operation, all patients were examined and interviewed daily. Complications detected by the examining physician, who was not aware of the patient's group assignment, were recorded. Duration of hospital stay was recorded.

\section{Outcome Measurements}

The primary end point was intraoperative urinary output. Secondary end points were serum creatinine concentrations on PODs 1 through 3 and the number of complications (postoperative mortality, pulmonary complications [pneumonia, atelectasis, acute respiratory distress syndrome, pulmonary embolism], cardiac complications [arrhythmias, myocardial infarction, pulmonary edema], cerebral complications [stroke, transient ischemic attack], renal complications [renal dysfunction defined as creatinine $>50 \%$ upper limit of normal values], infectious complications [sepsis, urinary tract infections, wound infection], surgical complications [protracted or major air leak, hemothorax]). Clinical data were collected and analyzed by bedside clinicians and investigators (E.D., B.C., Y.B.) blinded to patients' group assignment.

\section{Statistical Analysis}

Categoric data were analyzed with the $\chi^{2}$ test or Fisher exact test. Differences between the means and medians of the groups were compared with the Student $t$ test and the Mann-Whitney test, respectively. Data within each group were analyzed with analysis of variance for repeated measurements. When appropriate, post hoc analyses were performed with the Tukey test. Exact confidence intervals were computed for the overall rate of complications. Analysis was performed with Statistical Analysis System software (version 6.12; SAS Institute, Cary, NC). Results are expressed as mean $\pm \mathrm{SD}$ or median and range. A minimum sample size of 78 patients was calculated to detect a difference of $40 \mathrm{~mL}$ between the groups in primary outcome (intraoperative urinary output), with a power of $80 \%$, assuming an $\mathrm{SD}$ of $120 \mathrm{~mL}$ and a 2 -sided $P$ value of .05 .

\section{RESULTS \\ Study Population}

Patient disposition is shown in Figure 2. A total of 102 eligible patients who were randomly allocated to either low- or high-volume intraoperative fluid management (51 in each group) received the intervention and completed the study. The groups were similar in age, sex, body weight, and ASA score. Patient characteristics are summarized in Table 1 . There was no difference between the 2 surgeons with respect to their treatment of the groups.

Surgical data are listed in Table 2. Eighty-one percent of study patients underwent VAT lobectomy. The majority of these underwent VATS right lobectomy (51 of 83 lobectomies; $61 \%$ ). Duration of surgery was not significantly different between the groups. In addition, the volumes of surgical bleeding were similar. Intraoperatively, none of the patients required blood or blood product transfusion. Tracheal extubation was accomplished for all patients before arrival at the intensive care unit.

\section{Outcomes}

Primary outcome. Significantly $(P<.0001)$ more fluids were administered intraoperatively to patients in the high-volume compared with the low-volume protocol group 


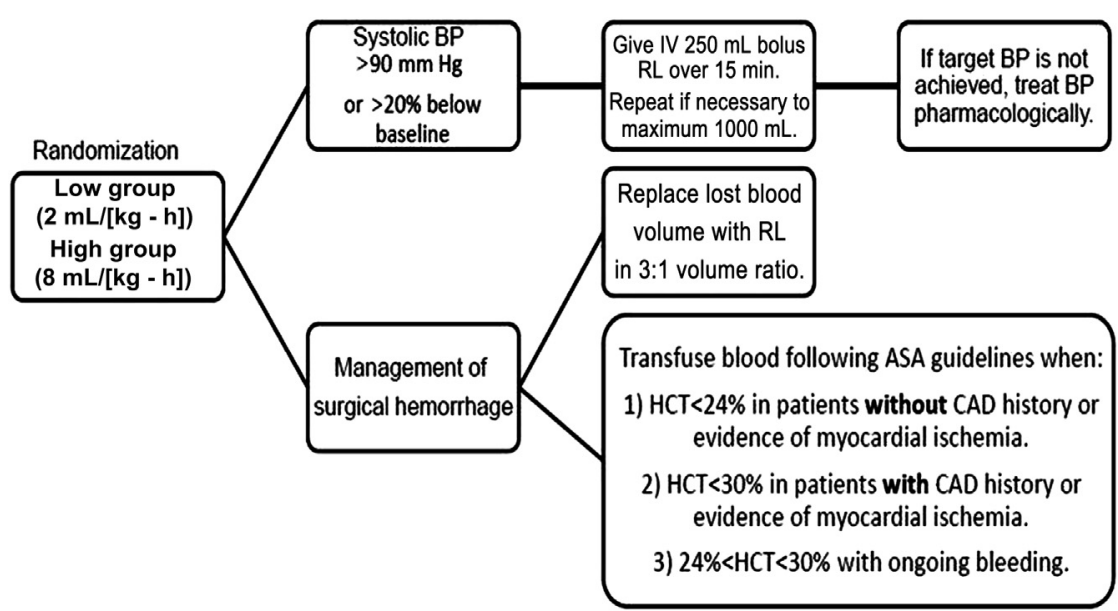

FIGURE 1. Algorithm for intraoperative fluid and blood administration. $B P$, Blood pressure; $I V$, intravenous; $R L$, Ringer's lactate solution; $A S A$, American Society of Anesthesiologists; $H C T$, hematocrit; $C A D$, coronary artery disease.

$(2131 \pm 850 \mathrm{~mL}$ vs $1035 \pm 652 \mathrm{~mL}$, respectively, $P<.0001)$. Regardless of the amount of fluids administered intraoperatively (approximately twice as much in the high- volume group), urinary output was not significantly different between the groups, with a median of $300 \mathrm{~mL}$ in both groups (high-volume group $371 \pm 241 \mathrm{~mL}$, low-volume

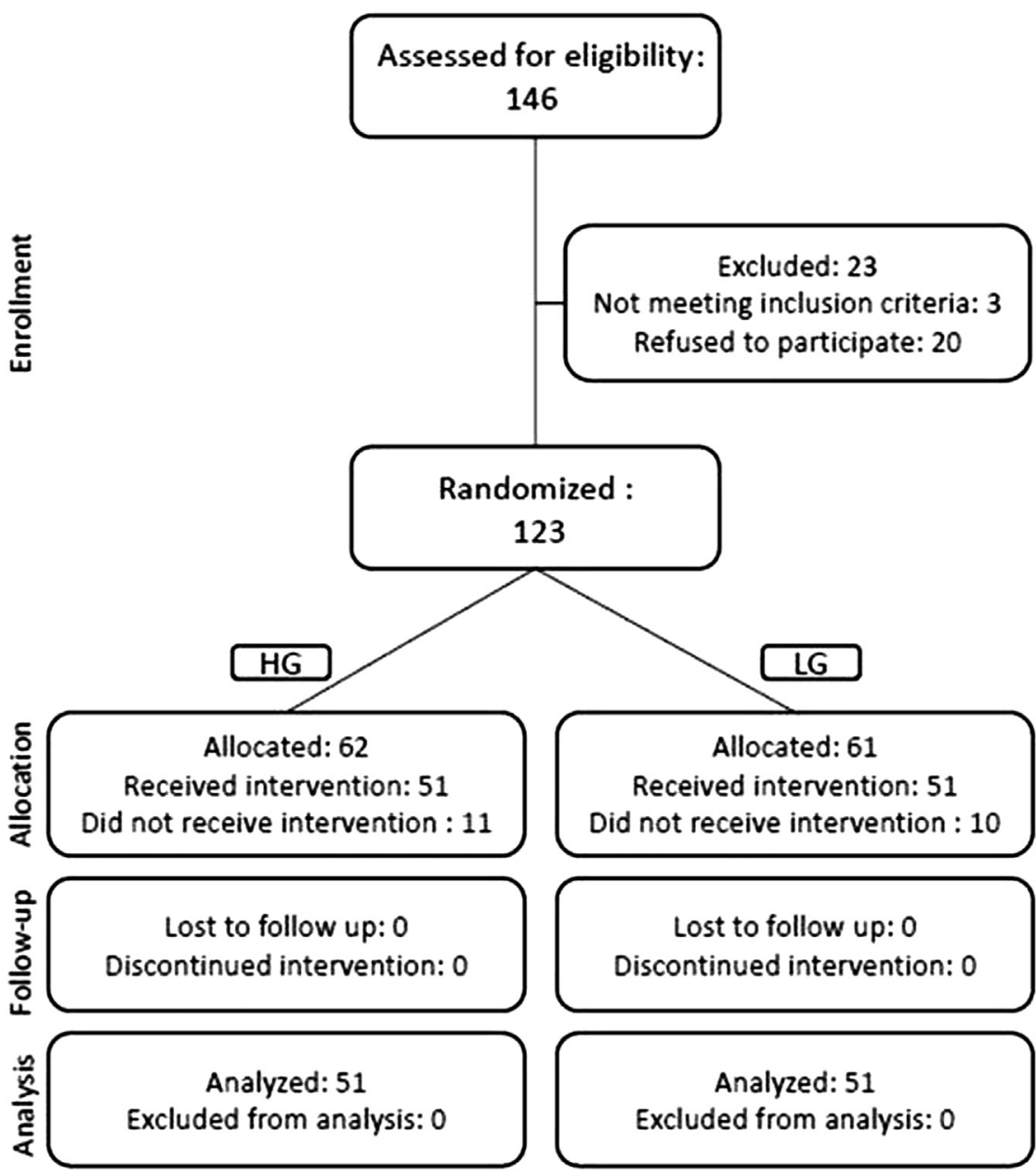

FIGURE 2. Trial profile. $H G$, High-volume group; $L G$, low-volume group. 
TABLE 1. Patient characteristics

\begin{tabular}{lccc}
\hline \multicolumn{1}{c}{ Group } & $\begin{array}{c}\text { High volume } \\
(\mathbf{n}=\mathbf{5 1})\end{array}$ & $\begin{array}{c}\text { Low volume } \\
(\mathbf{n}=\mathbf{5 1})\end{array}$ & $\boldsymbol{P}$ value \\
\hline Sex (male/female ratio) & $26: 25$ & $21: 30$ & .32 \\
Age (y, mean $\pm \mathrm{SD})$ & $64 \pm 10$ & $65 \pm 11$ & .70 \\
Weight $(\mathrm{kg}$, mean $\pm \mathrm{SD})$ & $75 \pm 16$ & $75 \pm 15$ & .93 \\
ASA $1 / 2 / 3^{*}$ & $0: 30: 21$ & $2: 31: 18$ & .35 \\
Hyperlipidemia & $25(49 \%)$ & $20(39 \%)$ & .32 \\
Hypertension & $26(51 \%)$ & $22(43 \%)$ & .43 \\
Ischemic heart disease & $10(20 \%)$ & $4(8 \%)$ & .08 \\
Diabetes & $14(27 \%)$ & $7(14 \%)$ & .87 \\
Pulmonary disease & $15(29 \%)$ & $13(25 \%)$ & .66 \\
$\beta$-Blocker treatment & $13(25 \%)$ & $10(20 \%)$ & .48 \\
\hline
\end{tabular}

Values are number of patients with percentage unless otherwise specified. There were no significant differences between the groups. ASA, American Society of Anesthesiologists; $S D$, standard deviation. *Breakdown of patients in American Society of Anesthesiologists classes 1, 2, and 3.

group $352 \pm 215 \mathrm{~mL} ; P>.05$; Table 2). Significant numbers of patients in both groups ( $36 \%$ and $54 \%$ of the patients in the high-volume group and the low-volume group, respectively $P=.1$ ) had intraoperative urinary output lower than $1.0 \mathrm{~mL} /(\mathrm{kg} \cdot \mathrm{h})$.

The mean volume of postoperative fluids administered was similar between the groups (data not shown).

Secondary and other outcomes. Creatinine serum levels. Preoperative as well as postoperative (PODs 1 and 3) creatinine serum levels were similar between the groups

TABLE 2. Operative data

\begin{tabular}{|c|c|c|c|}
\hline Group & $\begin{array}{l}\text { High volume } \\
\quad(\mathrm{n}=51)\end{array}$ & $\begin{array}{l}\text { Low volume } \\
\quad(\mathbf{n}=\mathbf{5 1})\end{array}$ & $\begin{array}{c}P \\
\text { value }\end{array}$ \\
\hline \multicolumn{4}{|l|}{ VATS procedures } \\
\hline Right VATS & $31(61 \%)$ & $28(55 \%)$ & .55 \\
\hline Right segmentectomy & $6(12 \%)$ & $2(4 \%)$ & \\
\hline Right lobectomy & $25(49 \%)$ & $26(51 \%)$ & \\
\hline Left VATS & $20(39 \%)$ & $23(45 \%)$ & .55 \\
\hline Left segmentectomy & $5(10 \%)$ & $6(12 \%)$ & \\
\hline Left lobectomy & $15(29 \%)$ & $17(33 \%)$ & \\
\hline \multicolumn{4}{|l|}{ Intraoperative data } \\
\hline $\begin{array}{l}\text { Duration of surgery } \\
\text { including anesthesia } \\
\text { (min, mean } \pm \mathrm{SD})\end{array}$ & $233 \pm 70$ & $230 \pm 82$ & .81 \\
\hline $\begin{array}{l}\text { Total fluid administered } \\
\quad(\mathrm{mL}, \text { mean } \pm \mathrm{SD})\end{array}$ & $2131 \pm 850$ & $1035 \pm 652$ & $<.0001$ \\
\hline $\begin{array}{l}\text { Blood loss }(\mathrm{mL} \\
\text { mean } \pm \mathrm{SD})\end{array}$ & $229 \pm 153$ & $217 \pm 200$ & .87 \\
\hline $\begin{array}{l}\text { Patients receiving blood } \\
\text { transfusion }\end{array}$ & 0 & 0 & \\
\hline $\begin{array}{l}\text { Patients receiving blood } \\
\text { products }\end{array}$ & 0 & 0 & \\
\hline $\begin{array}{l}\text { Intraoperative urinary } \\
\text { output }(\mathrm{mL}, \text { median and } \\
\text { range) }\end{array}$ & $300(70-1100)$ & $300(20-900)$ & .08 \\
\hline
\end{tabular}

Values are number of patients with percentage except as marked. VATS, Videoassisted thoracoscopic surgery; $S D$, standard deviation.
(Figure 3). Creatinine serum levels were significantly lower on PODs 1 and 3 than were baseline values in both groups. None of the patients had renal dysfunction during hospitalization. Patients who had low urinary output $(<1.0 \mathrm{~mL} /[\mathrm{kg}$. $\mathrm{h}]$ ), regardless of group assignment (high- or low-volume fluid management group), had similar creatinine values at all time points relative to patients who had more than 1.0 $\mathrm{mL} /[\mathrm{kg} \cdot \mathrm{h}]$ of urinary volume. Among those with a urinary output lower than $1.0 \mathrm{~mL} /(\mathrm{kg} \cdot \mathrm{h})$, creatinine levels were $1.03 \pm 0.17,1.00 \pm 0.23$, and $0.97 \pm 0.17 \mathrm{mg} / \mathrm{dL}$ at baseline
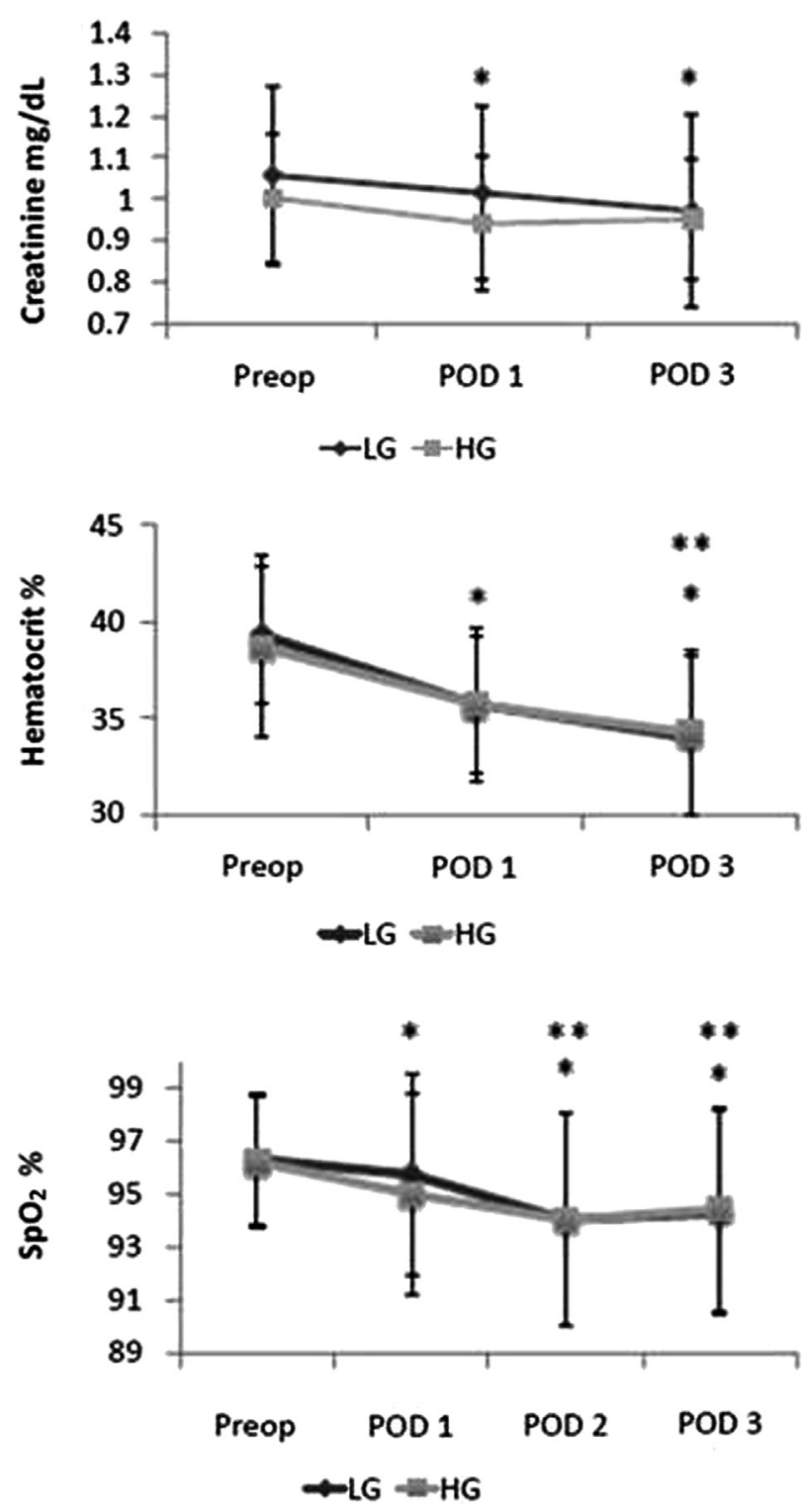

FIGURE 3. Perioperative (day before surgery [Preop] and postoperative day $[P O D] 1,2$, or 3 ) laboratory and oxygen saturation data: serum concentration of creatinine, hematocrit, and oxygen saturation by pulse oximetry $\left(\mathrm{Spo}_{2}\right)$. LG, Low-volume group; $H G$, high-volume group. Asterisk indicates $P<.0001$ compared with preoperative value; double asterisk indicates $P<.0001$ compared with postoperative day 1 . 
and on PODs 1 and 3, respectively; among those with a urinary output greater than $1.0 \mathrm{~mL} /(\mathrm{kg} \cdot \mathrm{h})$, creatinine levels were $1.04 \pm 0.19,1.00 \pm 0.15$, and $0.97 \pm 0.22 \mathrm{mg} / \mathrm{dL}$ at baseline and on PODs 1 and 3, respectively.

Complications. Eighteen major complications were diagnosed postoperatively, 9 in each group (Table 3). One patient from the high-volume group died on POD 4. This was a 66-year-old woman who was found dead in her bed at $5 \mathrm{AM}$, half an hour after a routine vital signs checkup that showed no abnormal parameters. Her medical history included hypertension, dyslipidemia, and severe chronic obstructive pulmonary disease related to heavy smoking. She underwent a left lobectomy, and her surgery and recovery were uneventful until her sudden death.

Cardiac arrhythmia was the most common cardiac class of complication, observed in 4 patients $(4 \%)$. Atelectasis was the most common pulmonary complication, occurring in 3 patients $(3 \%)$. Seven patients $(7 \%)$ had a significant air leak after resection.

Laboratory data. In the immediate postoperative period (PODs 1 and 3), hematocrit concentration decreased significantly $(P<.001)$ in both groups and was not different between the groups. Postoperative oxygen saturation decreased significantly on POD 1, with a further decrease on POD 3. Values were not different between groups at all time points (Figure 3).

Postoperative course. The time until the patient resumed drinking and consumed soft food was also not significantly different between the groups (data not shown). Duration of hospital stay was not significantly different between groups: $5.5 \pm 3.4$ days and $5.8 \pm 2.7$ days in the high- and lowvolume groups, respectively.

\section{DISCUSSION}

One of the risk factors for pulmonary complications after lung resection is excessive perioperative fluid administration. This association between increased fluid administration and postoperative lung injury, which was originally reported

TABLE 3. Postoperative major complications and death

\begin{tabular}{lcc}
\hline \multicolumn{1}{c}{ Complication } & High volume & Low volume \\
\hline Cardiac & & \\
$\quad$ Atrial fibrillation & 2 & 2 \\
$\quad$ Pulmonary edema & 1 & 0 \\
Pulmonary & 1 & \\
$\quad$ Atelectasis & 1 & 0 \\
$\quad$ Pneumonia & 1 & 0 \\
$\quad$ Pulmonary embolism & & \\
Surgical & 3 & 4 \\
$\quad$ Prolonged air leakage & 0 & 1 \\
$\quad$ Hemothorax & 1 & 0 \\
Death & $10(19.6 \%)$ & $9(17.6 \%)$ \\
Combined complications and death* & & \\
All data represent number of patients. $* P=.8$. & &
\end{tabular}

by Zeldin and colleagues, ${ }^{1}$ has been validated in much larger studies. $^{2-7}$ A meticulous approach to fluid therapy is therefore endorsed by all clinicians.

Perioperative fluid administration is dictated by several parameters. A recent survey with the ASA and the European Society of Anesthesiologists by Cannesson and coworkers ${ }^{8}$ assessed current hemodynamic management practices for patients undergoing surgery. Cannesson and coworkers ${ }^{8}$ found that urinary output was among the most widely used indicators for volume expansion, with $83 \%$ of the ASA respondents and $77 \%$ of the European Society of Anesthesiologists respondents reporting that they administered fluids in response to reduced urinary output. Indeed, intraoperative low diuresis often initiates several actions by the treating physician, among them the administration of intravenous fluids.

We evaluated the effect of intraoperative fluid management on urinary output in patients undergoing elective VATS for lung resection. Our randomized, controlled trial revealed that the amount of fluid administered intraoperatively, in the range of 2 to $8 \mathrm{~mL} /(\mathrm{kg} \cdot \mathrm{h})$, had no significant effect on urinary output; that is, there was no association between increased fluid volume administration and augmented urinary output. The study also demonstrated that regardless of the amount of fluid administered, reduced intraoperative urinary output $(<1 \mathrm{~mL} /[\mathrm{kg} \cdot \mathrm{h}])$ could occur but was not associated with postoperative renal dysfunction. This suggests that limiting the total volume of crystalloid administered, as indicated in VATS, can be tolerated.

Recently, in a comprehensive review, Hahn ${ }^{9}$ summarized his and others' work regarding fluid kinetics in the conscious patient versus the anesthetized patient. With a volume kinetics method for analyzing and simulating the distribution and elimination of infusion fluids, he showed that the clearance of fluids during general anesthesia is only a small fraction (15\%-20\%) of that observed in conscious volunteers. ${ }^{11-13}$ Clearance of infused fluids is even lower during laparoscopy. ${ }^{10,14}$ Only a limited volume of urine is thus produced, regardless of how much fluid is given. The cause for the blunted diuretic response to plasma volume expansion during anesthesia and surgery is poorly understood but probably is related to vasodilatation, hypotension, preoperative psychologic stress or dehydration, and activation of the renin-aldosterone hormonal axis. Further studies focusing on interventions that will result in better matching of urinary excretion and fluid load are needed. One such study that has already been done $^{15}$ reported better fluid clearance of infused fluids with the intraoperative use of agents (esmolol, a $\beta_{1}$-receptor blocker, and phenylephrine, an $\alpha_{1}$-adrenergic agonist) that manipulate the renin-angiotensin-aldosterone system and the adrenergic system, which are activated during anesthesia. ${ }^{16}$

Prerenal acute tubular necrosis has long been thought to be a prominent cause of postoperative renal dysfunction. ${ }^{17}$ As 
a result, surgeons and anesthesiologists attempt to maintain renal blood flow by a variety of strategies, one of which is intravenous hydration. Intraoperative urinary output is therefore watched closely as a measure of success with this goal. ${ }^{18}$ Data from this study, however, show that reduced intraoperative urinary output is not associated with clinically relevant renal dysfunction. This finding is in agreement with previous studies in obese patients undergoing bariatric surgery, in whom intraoperative oliguria was not associated with perioperative increase in serum creatinine level. ${ }^{19,20}$ Some of the causes for oliguria in laparoscopic bariatric surgery are unique to that operation (direct pressure effect of pneumoperitoneum on the renal vasculature, resulting in reduced renal blood flow), however, and therefore may not be relevant to our patients undergoing VATS. Others have evaluated risk factors for postoperative acute renal failure in a larger patient population. In a comprehensive study ${ }^{21}$ of patients with previously normal renal function undergoing major noncardiac surgery, Kheterpal and associates ${ }^{21}$ could not confirm the assumption that reduced intraoperative urinary output predicts future renal failure.

Previous studies in patients undergoing open thoracotomy for lung resection showed increased perioperative fluid administration to be an independent risk factor associated with lung injury. ${ }^{1-7}$ Ours is the first study to evaluate fluid management during VATS. The data demonstrate that, at least in the range of fluids evaluated, complication rate is not significantly different between the high- and lowvolume groups. This could be explained by an inadequate sample size, because complication rate was a secondary end point, and by the inclusion of patients undergoing resection of relatively small parts of the lungs (segmentectomy, in contrast to pneumonectomy and lobectomy), where lung injury is less likely to occur. A larger study is therefore warranted to confirm whether patients undergoing VATS are more tolerant of fluid load.

This study has several limitations. The study was not conducted in a totally blinded fashion. The anesthesiologist treating the patient during the intraoperative period was not blinded to the patient's group assignment; however, the indications for additional fluid administration were standardized. Moreover, postoperative adverse outcomes were detected by the examining physician, who was not aware of the patient's assignment. Another limitation is that our study evaluated only 2 volumes of fluids.

In conclusion, this study in patients undergoing VATS offers further evidence that monitoring of urinary output is ineffective at indicating fluid status during anesthesia and surgery; urinary excretion simply increases little, despite the presence of a surplus of intravascular fluid. Because patients undergoing VATS are susceptible to intraoperative fluid overload, these data suggest that fluid management during VATS should not be guided by urinary volume as practiced in nonoperative scenarios.

We thank A. Knaani, a consultant biostatistician, for her assistance with programming the statistical analyses.

\section{References}

1. Zeldin RA, Normandin D, Landtwing D, Peters RM. Postpneumonectomy pulmonary edema. J Thorac Cardiovasc Surg. 1984;87:359-65.

2. Licker M, de Perrot M, Spiliopoulos A, Robert J, Diaper J, Chevalley C, et al. Risk factors for acute lung injury after thoracic surgery for lung cancer. Anesth Analg. 2003;97:1558-65.

3. Mizuno Y, Iwata H, Shirahashi K, Takamochi K, Oh S, Suzuki K, et al. The importance of intraoperative fluid balance for the prevention of postoperative acute exacerbation of idiopathic pulmonary fibrosis after pulmonary resection for primary lung cancer. Eur J Cardiothorac Surg. 2012;41:e161-5.

4. Alam N, Park BJ, Wilton A, Seshan VE, Bains MS, Downey RJ, et al. Incidence and risk factors for lung injury after lung cancer resection. Ann Thorac Surg. 2007;84:1085-91; discussion 1091.

5. Waller DA, Keavey P, Woodfine L, Dark JH. Pulmonary endothelial permeability changes after major lung resection. Ann Thorac Surg. 1996;61:1435-40.

6. Caras WE. Postpneumonectomy pulmonary edema: can it be predicted preoperatively? Chest. 1998;114:928-31.

7. Parquin F, Marchal M, Mehiri S, Hervé P, Lescot B. Post-pneumonectomy pulmonary edema: analysis and risk factors. Eur J Cardiothorac Surg. 1996; 10:929-32; discussion 933.

8. Cannesson M, Pestel G, Ricks C, Hoeft A, Perel A. Hemodynamic monitoring and management in patients undergoing high risk surgery: a survey among North American and European anesthesiologists. Crit Care. 2011;15:R197.

9. Hahn RG. Volume kinetics for infusion fluids. Anesthesiology. 2010;113:470-81.

10. Olsson J, Svensén CH, Hahn RG. The volume kinetics of acetated Ringer's solution during laparoscopic cholecystectomy. Anesth Analg. 2004;99:1854-60; table of contents.

11. Ewaldsson CA, Hahn RG. Kinetics and extravascular retention of acetated Ringer's solution during isoflurane or propofol anesthesia for thyroid surgery. Anesthesiology. 2005;103:460-9.

12. Brauer KI, Svensén C, Hahn RG, Traber LD, Prough DS. Volume kinetic analysis of the distribution of $0.9 \%$ saline in conscious versus isoflurane-anesthetized sheep. Anesthesiology. 2002;96:442-9.

13. Svensén C, Hahn RG. Volume kinetics of Ringer solution, dextran 70, and hypertonic saline in male volunteers. Anesthesiology. 1997;87:204-12.

14. Holte K, Hahn RG, Ravn L, Bertelsen KG, Hansen S, Kehlet H. Influence of "liberal" versus "restrictive" intraoperative fluid administration on elimination of a postoperative fluid load. Anesthesiology. 2007;106:75-9.

15. Li YH, Zhu HB, Zheng X, Chen HJ, Shao L, Hahn RG. Low doses of esmolol and phenylephrine act as diuretics during intravenous anesthesia. Crit Care. 2012;16: R18.

16. Norberg A, Hahn RG, Li H, Olsson J, Prough DS, Børsheim E, et al. Population volume kinetics predicts retention of $0.9 \%$ saline infused in awake and isoflurane-anesthetized volunteers. Anesthesiology. 2007;107:24-32.

17. Brezis M, Rosen S. Hypoxia of the renal medulla-its implications for disease. N Engl J Med. 1995;332:647-55.

18. Jacob M, Chappell D, Rehm M. Clinical update: perioperative fluid management. Lancet. 2007;369:1984-6.

19. Matot I, Paskaleva R, Eid L, Cohen K, Khalaileh A, Elazary R, et al. Effect of the volume of fluids administered on intraoperative oliguria in laparoscopic bariatric surgery: a randomized controlled trial. Arch Surg. 2012;147:228-34.

20. Nguyen NT, Perez RV, Fleming N, Rivers R, Wolfe BM. Effect of prolonged pneumoperitoneum on intraoperative urine output during laparoscopic gastric bypass. J Am Coll Surg. 2002;195:476-83.

21. Kheterpal S, Tremper KK, Englesbe MJ, O'Reilly M, Shanks AM, Fetterman DM, et al. Predictors of postoperative acute renal failure after noncardiac surgery in patients with previously normal renal function. Anesthesiology. 2007;107:892-902. 